\title{
A Study on Practitioner's Perceptions on Early Screening of Autism Spectrum Disorder
}

\author{
Hyun-Jung Sunwoo, Dong-Hyun Noh, Kyung Mee Kim, Joo-Hyun Kim, and Hee Jeong Yoo \\ Division of Child and Adolescent Psychiatry, Department of Psychiatry, Seoul National University Bundang Hospital, \\ Seoul National University College of Medicine, Seongnam, Korea
}

\section{자폐스펙트럼장애의 조기선별에 대한 관련 분야 종사자의 인식 조사}

\author{
선우현정, 노동현, 김경미, 김주현, 유희정 \\ 서울대학교 의과대학 분당서울대학교병원 정신건강의학과
}

\begin{abstract}
Objectives: The purpose of this study is to investigate the professional knowledge and perceptions of the early screening of Autism Spectrum Disorder (ASD) in practitioners who have contact with patients with ASD.

Methods: A survey was carried out among 674 practitioners in total, where practitioners are defined as those who work at primary medical centers, public institutions, educational institutions and treatment institutions. The survey was carried out both online and offline, and it mainly focused on 1) knowledge about ASD symptoms, 2) knowledge about the early screening of ASD, 3) measures taken after ASD detection, 4) thoughts on the development of early screening tools for ASD, and 5) the current status of ASD treatment. The data collected were analyzed through descriptive statistics, analysis of frequency and cross tabulation analysis using SPSS WIN 22.0.

Results: The results of this study suggest that the practitioners were not aware of the exact symptoms of ASD and their professional knowledge and the environment for early screening were insufficient. Furthermore, very few and inappropriate measures were taken after the detection of ASD. In addition, there was a high demand for early ASD screening tools to be used on site and, regarding treatment, the significance of the implementation of evidence based treatments as well as the continuity of relevant research came to the fore.

Conclusion: It seems that there is a lack of knowledge and perception of the early screening of ASD and that education and training among practitioners is urgently required. This issue is discussed in more detail in the paper.
\end{abstract}

Key Words: Autism spectrum disorder; Early screening; Experts' perception.

Received: September 1, 2016 / Revision: October 12, 2016 / Accepted: February 4, 2017

Address for correspondence: Hee Jeong Yoo, Division of Child and Adolescent Psychiatry, Department of Psychiatry, Seoul National University Bundang Hospital, Seoul National University College of Medicine, 82 Gumi-ro 173beon-gil, Bundang-gu, Seongnam 13620, Korea

Tel: +82-31-787-7436, Fax: +82-31-787-4058, E-mail: hjyoo@snu.ac.kr

\section{서 론}

자폐스펙트럼장애(Autism Spectrum Disorder, ASD)는 사 회적 상호작용 및 의사소통의 손상, 그리고 제한된 관심범위 와 반복적 행동을 주요 증상으로 하는 신경발달 장애로서, 최 근 국내외에서 유병률의 증가추세를 보이고 있는 장애 중 하 나이다. 얼마 전 미국을 포함한 여러 국가에서 조사된 바에 의 하면, ASD 유병률이 인구의 $1 \%$ 에 달하는 것으로 파악되었으 며, ${ }^{1)}$ 국내에서는 $2.64 \%$ 의 높은 수치로 조사된 연구도 발표된 바 있다. ${ }^{2)}$ 이러한 높은 비율이 역치하 사례들을 포함하는 진단

This is an Open Access article distributed under the terms of the Creative Commons Attribution Non-Commercial License (http://creativecommons.org/licenses/by-nc/4.0) which permits unrestricted non-commercial use, distribution, and reproduction in any medium, provided the original work is properly cited.
기준의 확장이나 증가된 인식, 연구 방법의 차이를 반영하는지, 아니면 실제 $\mathrm{ASD}$ 의 발생 빈도 증가를 반영하는지는 불분명 하나, ${ }^{1)}$ 앞으로 $\mathrm{ASD}$ 가 점차 의학적 측면뿐만 아니라, 사회, 복지, 교육 영역 등 다학제적인 접근을 필요로 할 것으로 판단된다.

이처럼 전체 인구 중 $\mathrm{ASD}$ 의 유병률이 높게 나타나고 있기에 사회, 경제적 부담을 줄이고자 조기개입과 자문을 위한 변화 들이 감지되고 있기는 하지만, 실제로 $\mathrm{ASD}$ 의 조기개입의 중 요성은 그 장애특성에 기인한다. $\mathrm{ASD}$ 는 장애의 특성상 증상 이 매우 어린 시기부터 나타나기 때문에 일찍 증상을 발견할 수 있으며, 유전자의 표현형이 완전히 발현되기 이전에 빠르게 개입할 경우 환경적인 영향에 의해 증상을 보다 완화할 수 있 다고 밝혀지고 있다. ${ }^{3,4)}$ 따라서 $\mathrm{ASD}$ 의 치료적 개입은 보다 이 른 시기에 개입할수록 증상 개선의 폭이 높고, ${ }^{5,6)}$ 더욱 긍정적 
인 예후를 기대할 수 있을 것이다. ${ }^{7}$

$\mathrm{ASD}$ 의 조기발견은 효과적인 조기개입의 첫걸음이 된다. 정 신질환진단 및 통계 편람(Diagnostic and Statistical Manual of Mental Disorders, DSM)에서 언급하고 있는 ASD 증상 발견 시기를 살펴보면, 이전까지 진단기준으로 활용되어 온 DSM-IV에서 '3세 이전에 시작된다'로 명시했었던 것이," 최 근 개정된 DSM-5에서는 '초기발달 시기부터 나타난다'고 수 정되었으며, 전형적인 경우 12 24개월에 증상이 발견될 수 있 고, 지연이 심각한 경우 12 개월 이전에도 발견할 수 있다고 명 시되어 있다. ${ }^{1)}$ 이는 $\mathrm{ASD}$ 증상 조기발견의 중요성을 강조한 그동안의 많은 연구결과들을 반영한 것이라고 하겠으며, ${ }^{9-11)}$ 이로 인해 상당히 이른 시기부터 $\mathrm{ASD}$ 의 증상을 발견할 수 있 음을 알 수 있다. 그러나, 이와 같은 증상의 조기발견 가능성에 도 불구하고, 현장에서 $\mathrm{ASD}$ 의 조기진단은 잘 이루어지지 못 하고 있는 실정이다.,11) 부모들이 자녀의 $\mathrm{ASD}$ 증상을 초기에 잘 인식하지 못하는 이유이기도 하지만, ${ }^{12,13)}$ 의사, 사회복지사, 교사, 치료사 등의 $\mathrm{ASD}$ 관련 종사자들의 $\mathrm{ASD}$ 에 대한 인식이 나 적극적인 대처가 부족하기 때문인 것도 한몫을 하고 있는 것으로 추정된다.

국내 관련 종사자들의 $\mathrm{ASD}$ 에 대한 인식 조사는 활발하지 못한 실정이며, 그나마 교육기관 교사들을 대상으로 하는 연 구가 일부 보고된 바 있다. 한 연구에서는 재직 중인 보육교사 들의 약 $40 \%$ 가 $\mathrm{ASD}$ 를 포함한 장애 영유아가 입소하는 것에 대해 부정적인 시각을 지니고 있다고 보고하였다. ${ }^{14)}$ 또 다른 연구에서는 유치원 교사들이 현장에서 의사소통 및 상호작 용의 결손 등 $\mathrm{ASD}$ 의 진단적 특징들이 잘 인식되지 않는 편이 라고 보고하였는데, 구체적인 면담 내용을 살펴보면 대부분 의 교사들이 $\mathrm{ASD}$ 의 핵심 증상보다는 그 밖의 단편적인 특징 을 기준 삼아 판단하고 있는 경향이 있었다. ${ }^{15)}$ 한편, $\mathrm{ASD}$ 장애 진단 시기를 조사한 연구에서는 다른 장애와 비교하였을 때, $\mathrm{ASD}$ 의 장애진단 시기가 처음 문제를 발견한 시기와 가장 격 차가 크다고 보고하면서, 이러한 차이의 이유에 대해 부모들 은 '자라면서 나아질 것이라고 여겨서'라고 응답한 경우가 $52.2 \%$ 로 가장 많았고, '너무 어려 의사가 예후를 보고 진단할 것을 권유하여'라고 응답한 경우가 $39.7 \%$ 로 그 다음 순으로 많았다고 하였다. ${ }^{16)}$ 이와 같은 결과를 보았을 때 사실상 전문 의들조차 $\mathrm{ASD}$ 조기진단을 위한 구체적인 지식을 갖추지 못 하고 있는 상태로 예상된다. 그 밖에 다른 관련 종사자들의 $\mathrm{ASD}$ 에 대한 인식을 살펴본 연구는 찾아보기 힘든 실정이었다.

$\mathrm{ASD}$ 의 증상을 처음 인식하는 사람으로 부모(66.2\%)가 가 장 많은 비율을 차지하지만, 교육기관 교사(15.4\%)와, 영유아 검진 의사 등의 다른 종사자들(13.8\%)도 증상의 첫 발견에 중 요한 몫을 할 뿐만 아니라, 첫 진단 실시 기관이 대학병원 소
아정신과(40.4\%) 이외에도 아동발달센터(27.6\%), 개인 소아정 신과 $(25.5 \%)$ 등의 정신과 의사가 아닌 아동발달 관련 임상가 들의 ASD 진단 및 평가 비율도 상당히 높은 것으로 보고되는 바, ${ }^{17)}$ 여러 분야 종사자들의 $\mathrm{ASD}$ 조기발견을 위한 역량에 대 해 조사하여 현 실태를 점검하는 과정이 필요해 보인다. 이에 본 연구는 영유아 $\mathrm{ASD}$ 를 접할 수 있는 관련 기관, 즉 일차의 료기관, 공공기관, 교육기관, 치료기관 등에 종사하고 있는 전 문인력들을 대상으로 $\mathrm{ASD}$ 와 관련된 지식과 인식에 대해 조 사하고자 하였다. 이러한 결과를 바탕으로 $\mathrm{ASD}$ 의 조기선별 을 위한 현장의 실태가 어떠한지 알아보고, $\mathrm{ASD}$ 의 조기발견과 관련된 대책을 세우기 위한 기초자료를 마련하고자 한다.

\section{방 법}

\section{대 상}

본 연구의 대상은 $\mathrm{ASD}$ 와 접촉할 수 있는 일차진료기관, 공 공기관, 교육기관, 치료기관 등에 근무하고 있는 종사자 집단 으로, 총 674명이었다. 연구 대상을 모집하기 위하여 오프라 인과 온라인의 두 가지 방법을 활용하였는데, 오프라인의 경 우, 각종 학회행사와 교육, 연수 현장에 연구진이 직접 방문하 여 질문지를 배부하고 수거하는 방식으로 실시하였으며, 온라 인의 경우 연구진이 유선으로 연구과정에 대해 안내하고 질 문지를 접속할 수 있는 온라인 주소를 개별적으로 발송하여 응답할 수 있도록 하였다. 온라인 주소 발송의 구체적인 방식 은 일차진료기관, 교육기관, 치료기관은 학회행사 참여자와 지인을 중심으로 하는 눈덩이 표집(snowball sampling)이 주 를 이루었고, 공공기관의 경우 지역별 공공기관 목록을 작성 하여 전 지역에 유선으로 연락을 취하여 희망하는 기관에 이 메일로 온라인 주소를 발송하였다.

\section{도 구}

실태조사를 위해 사용된 질문지는 본 연구진이 자체 제작 한 질문지로 일차진료기관용 24문항, 공공기관 28 문항, 교육 기관 33문항, 치료기관 30문항으로 구성되어 있다. 질문지를 제작한 연구진은 소아정신과 전문의 2 인과 임상심리학 전공 석사 2 인, 아동학 전공 석사 1 인으로, 질문지의 초안을 소아정 신과 전문의 1 인(석사)과 임상심리학 전공자 1 인(석사)이 제작 하고, 제작과정에 참여하지 않은 소아정신과 전문의 1 인(박 사), 임상심리전문가 1 인(석사), 아동학 전공자 1 인(석사)이 검 토하여 수정, 보완하는 작업을 거쳐 완성되었다. 또한 공공기 관 및 교육기관을 대상으로 하는 질문지는 지역사회에서 실 제로 근무하고 있는 정신보건 전문요원(정신보건 사회복지사) 5 인 및 특수교사 2 인이 문구의 이해도, 문항의 난이도에 대해 
점검하였다. 모든 질문지는 객관식으로 구성되어 있으며, 각 문 항을 읽고 자신의 생각에 가장 가까운 답안을 한 가지 고르도 록 하였다. 질문지의 공통 문항은 성별, 연령, 근무지를 묻는 기본적인 3 문항을 포함하여, ASD 영유아의 방문 여부, 한 달 평균 방문인원, 찾아오는 경로, 의심 영유아의 연령층, 장애를 판단하는 기준이나 징후, 장애가 아니라고 판단한 기준, 진단 가능한 연령, 평가도구 비치 여부, 주로 사용하는 평가도구, 의 심 영유아에게 취하는 조치, 의심 영유아 부모에게 취하는 조 치, $\mathrm{ASD}$ 평정 도구에 대한 지식, 영유아 건강검진의 효율성에 관한 질문 4문항(일차진료기관의 경우 5 문항), 선별도구 개발 의 필요성에 관한 질문 3 문항, 기타 의견으로 구성되어 있다 (총 23문항). 이에 더해 기관별로 특징적인 질문을 추가하였는 데, 공공기관의 경우 구체적인 직역과 함께 $\mathrm{ASD}$ 의 정식명칭과 증상에 대한 지식 등 5 문항이 추가되었고, 교육기관의 경우 설 립유형, 학급유형, 학급편성, 교사 수, 교사 소지 자격증 등 기 초적인 정보와 함께 $\mathrm{ASD}$ 의 정식명칭과 증상에 대한 지식, 기 관 내 장애 전담 교사 비치 여부, 기관 내 $\mathrm{ASD}$ 영유아로 가장 문제가 되는 점 등 10 문항이 추가되었다. 마지막으로 치료기관 의 경우 근무기관 유형과 $\mathrm{ASD}$ 영유아 치료 종류(치료 기법), 치료 유형(개인, 집단치료 등), 호전 정도 등 치료와 관련된 6 문항을 추가하였다.

\section{절 차}

연구진이 제작한 질문지를 온라인, 오프라인 경로를 통해 배 부, 수거하였다. 2015년 8월부터 12월까지 진행된 설문조사에 서 총 배부된 설문지는 680부였으며, 불성실하게 응답한 6명 의 설문지를 제외하고 총 674 명의 설문지가 분석에 사용되었 다. 본 연구는 분당서울대학교병원 생명윤리심의위원회(Institutional Review Board, IRB)의 승인을 받았으며, 모든 설문 대상은 IRB 동의서에 직접 서명하였고, 설문에 참여한 자에게 는 소정의 기념품을 지급하였다.

\section{분석 방법}

연구 대상의 특성을 살펴보기 위하여 빈도와 백분율을 산 출하였고, $\mathrm{ASD}$ 와 관련된 현장의 실태를 조사하기 위해서 집 단별로 빈도와 백분율을 산출하였다. 한편, 각 직군별 실태의 차이가 있는지 살펴보기 위하여 집단별 분석을 실시하고자 하였으나, 집단의 규모가 동일하지 않고 살펴보고자 하는 범 주의 수가 많은 편이어서 의미 있는 분석을 하는 데 제한점이 있어 분석에서 제외되었다. 모든 자료는 SPSS version 22.0 (SPSS Inc., Chicago, IL, USA)으로 분석되었다.

\section{결 과}

\section{연구 대상의 사회인구학적 배경}

연구 대상은 총 674 명이었다. 직군은 일차진료기관 종사자가 $10.09 \%$, 공공기관 종사자가 $6.68 \%$, 교육기관 종사자가 $44.66 \%$, 치료기관 종사자가 $38.58 \%$ 로, 교육기관과 치료기관 종사자가 많은 비율을 차지하였다. 성별은 남자가 $8.01 \%$, 여성이 $90.21 \%$ 로 대부분 여성이 관련 분야에 종사하고 있었으며, 연령층은 30 대가 $38.87 \%$ 로 가장 많았고, 40 대가 $22.40 \%, 20$ 대가 $21.81 \%$ 로 대부분을 차지하였다(Table 1).

Table 1. Socio-demographic background of study subjects $(n=674)$

\begin{tabular}{|c|c|}
\hline Socio-demographic background & Frequency (\%) \\
\hline \multicolumn{2}{|l|}{ Job group and affiliated institution } \\
\hline \multicolumn{2}{|l|}{ Primary medical center } \\
\hline Pediatrics & $65(95.59)$ \\
\hline Family medicine & $1(1.47)$ \\
\hline Rehabilitation medicine & $1(1.47)$ \\
\hline Other & $1(1.47)$ \\
\hline Total & $68(100)$ \\
\hline \multicolumn{2}{|l|}{ Educational institutions } \\
\hline Nursery & $301(100)$ \\
\hline Total & $301(100)$ \\
\hline \multicolumn{2}{|l|}{ Public institutions } \\
\hline Health center & $1(2.22)$ \\
\hline Mental health center & $9(20.00)$ \\
\hline Child \& adolescent mental health center & $25(55.56)$ \\
\hline Other & $10(22.22)$ \\
\hline Total & $45(100)$ \\
\hline \multicolumn{2}{|l|}{ Treatment institutions } \\
\hline Public institutions & $58(22.31)$ \\
\hline Private treatment centers & $125(48.08)$ \\
\hline Private hospitals & $36(13.85)$ \\
\hline Other & $41(15.77)$ \\
\hline Total & $260(100)$ \\
\hline \multicolumn{2}{|l|}{ Age } \\
\hline $20 \mathrm{~s}$ & $147(21.81)$ \\
\hline $30 \mathrm{~s}$ & $262(38.87)$ \\
\hline $40 \mathrm{~s}$ & $151(22.40)$ \\
\hline $50 \mathrm{~s}$ & $84(12.46)$ \\
\hline 60 s and above & $16(2.37)$ \\
\hline Missing & $14(2.08)$ \\
\hline Total & $674(100)$ \\
\hline \multicolumn{2}{|l|}{ Gender } \\
\hline Male & $54(8.01)$ \\
\hline Female & $608(90.21)$ \\
\hline Missing & 12 (1.78) \\
\hline Total & $674(100)$ \\
\hline
\end{tabular}




\section{기관별 ASD 이용 실태}

각 기관별로 질문하였을 때, 모든 기관의 $60 \%$ 이상이 $\mathrm{ASD}$ 로 의심되는 아동이 기관을 이용하였다고 응답하였으며(Table 2), 이때 기관을 방문한 ASD 아동의 주요 연령층은 Table 3 과 같았다.

\section{$\mathrm{ASD}$ 관련 지식 실태}

$\mathrm{ASD}$ 아동이 방문하거나 이용할 수 있는 기관에서 근무하고 있는 종사자들의 $\mathrm{ASD}$ 와 관련된 지식수준을 살펴보기 위하 여, $\mathrm{ASD}$ 로 진단 가능한 연령과 $\mathrm{ASD}$ 증상에 대해 질문하였 다. 먼저 $\mathrm{ASD}$ 로 처음 진단 가능한 연령을 몇 세라고 생각하는 지 묻는 질문에 대해, 일차진료기관의 경우 2세 미만(35.29\%) 과 3세 미만(33.82\%)이라고 응답한 경우가 가장 많았고, 공공 기관의 경우 3세 미만(37.78\%)과 4세 미만(28.89\%), 교육기관 의 경우 3세 미만(38.87\%)과 2세 미만(30.23\%), 치료기관의 경 우 3세 미만(27.69\%)과 4세 미만(25.77\%)으로 응답한 경우가
가장 많았다(Table 4). 한편, $\mathrm{ASD}$ 가 의심되는 아동이 기관에 방문한 경험이 있다고 응답한 자에 한하여, 당시 방문한 영유 아가 $\mathrm{ASD}$ 라고 판단할 수 있는 기준이나 징후가 무엇이었는지 질문하자, 일차진료기관, 교육기관, 치료기관은 사회적 관심, 상호작용 문제 $(29.79,56.42,63.73 \%)$ 를 가장 많이 선택하였고, 공공기관만이 자극에 대한 과소, 과대반응 (35.71\%)을 가장 많 이 선택하였다(Table 5). 또, $\mathrm{ASD}$ 가 아니라고 판단했던 기준 이나 징후에 대해서는 일차진료기관과 공공기관에서는 '부모 보고에 의하면 형제자매, 친구와 놀이할 수 있다고 하였다 $(19.15,35.71 \%)$ '를 교육기관에서는 '가족과 눈맞춤이 가능하 다고 하였다(18.8\%)', 치료기관에서는 '가족과 긍정적인 애착 행동이 나타났다(17.65\%)를 가장 많이 선택하였다(Table 6).

\section{ASD 아동 선별 실태}

각 기관에 $\mathrm{ASD}$ 아동이 방문하였을 경우 이들을 선별할 수 있는 검사도구가 비치되어 있는지의 여부를 조사한 결과, 일

Table 2. Utilization of institutions by ASD infants [frequency (\%)]

\begin{tabular}{|c|c|c|c|c|c|}
\hline Response & Primary medical center & Public institutions & Educational institutions & Treatment institutions & Total \\
\hline Yes & $47(69.12)$ & $28(62.22)$ & $218(72.43)$ & $204(78.46)$ & $497(73.74)$ \\
\hline No & 21 (30.88) & 17 (37.78) & $83(27.57)$ & $56(21.54)$ & $177(26.26)$ \\
\hline Total & $68(100)$ & $45(100)$ & $301(100)$ & $260(100)$ & $674(100)$ \\
\hline
\end{tabular}

ASD: Autism Spectrum Disorder

Table 3. Major ASD age groups who visited an institution [frequency (\%)]

\begin{tabular}{|c|c|c|c|c|c|}
\hline Response & $\begin{array}{c}\text { Primary } \\
\text { medical center }\end{array}$ & $\begin{array}{c}\text { Public } \\
\text { institutions }\end{array}$ & $\begin{array}{l}\text { Educational } \\
\text { institutions }\end{array}$ & $\begin{array}{l}\text { Treatment } \\
\text { institutions }\end{array}$ & Total \\
\hline Below 1 year old & $0(0.00)$ & $0(0.00)$ & $2(0.92)$ & $0(0.00)$ & $2(0.40)$ \\
\hline $1-2$ years old (12-23 months) & $11(23.40)$ & $2(7.14)$ & $35(16.06)$ & $6(2.94)$ & $54(10.87)$ \\
\hline $2-3$ years old ( $24-35$ months) & $16(34.04)$ & $4(14.29)$ & $76(34.86)$ & $63(30.88)$ & $159(31.99)$ \\
\hline $3-4$ years old ( $36-47$ months) & $8(17.02)$ & $5(17.86)$ & $70(32.11)$ & $71(34.80)$ & $154(30.99)$ \\
\hline $4-6$ years old ( $48-71$ months) & $1(2.13)$ & $17(60.71)$ & $35(16.06)$ & $46(22.55)$ & $99(19.92)$ \\
\hline Missing & $11(23.40)$ & $0(0.00)$ & $0(0.00)$ & $18(8.82)$ & $29(5.84)$ \\
\hline Total & $47(100)$ & $28(100)$ & $218(100)$ & $204(100)$ & $497(100)$ \\
\hline
\end{tabular}

ASD: Autism Spectrum Disorder

Table 4. Appropriate age for initial ASD diagnosis [frequency (\%)]

\begin{tabular}{|c|c|c|c|c|c|}
\hline Response & $\begin{array}{c}\text { Primary } \\
\text { medical center }\end{array}$ & $\begin{array}{c}\text { Public } \\
\text { institutions }\end{array}$ & $\begin{array}{l}\text { Educational } \\
\text { institutions }\end{array}$ & $\begin{array}{l}\text { Treatment } \\
\text { institutions }\end{array}$ & Total \\
\hline Below 1 year old & $4(5.88)$ & $1(2.22)$ & $21(6.98)$ & $4(1.54)$ & $30(4.45)$ \\
\hline Below 2 years old & $24(35.29)$ & $12(26.67)$ & 91 (30.23) & $63(24.23)$ & $190(28.19)$ \\
\hline Below 3 years old & $23(33.82)$ & $17(37.78)$ & $117(38.87)$ & $72(27.69)$ & $229(33.98)$ \\
\hline Below 4 years old & $11(16.18)$ & $13(28.89)$ & 57 (18.94) & $67(25.77)$ & $148(21.96)$ \\
\hline Below 6 years old & $3(4.41)$ & $1(2.22)$ & $10(3.32)$ & $41(15.77)$ & $55(8.16)$ \\
\hline Below 12 years old & $0(0.00)$ & $1(2.22)$ & $5(1.66)$ & $8(3.08)$ & $14(2.08)$ \\
\hline Missing & $3(4.41)$ & $0(0.00)$ & $0(0.00)$ & $5(1.92)$ & $8(1.19)$ \\
\hline Total & $68(100)$ & $45(100)$ & $301(100)$ & $260(100)$ & $674(100)$ \\
\hline
\end{tabular}

ASD: Autism Spectrum Disorder 
Table 5. Symptoms that allow ASD detection [frequency (\%)]

\begin{tabular}{lccccc}
\hline \multicolumn{1}{c}{ Response } & $\begin{array}{c}\text { Primary } \\
\text { medical center }\end{array}$ & $\begin{array}{c}\text { Public } \\
\text { institutions }\end{array}$ & $\begin{array}{c}\text { Educational } \\
\text { institutions }\end{array}$ & $\begin{array}{c}\text { Treatment } \\
\text { institutions }\end{array}$ & Total \\
\hline Verbal communication problems & $13(27.66)$ & $0(0.00)$ & $24(11.01)$ & $14(6.86)$ & $51(10.26)$ \\
Non-verbal communication problems & $9(19.15)$ & $1(3.57)$ & $14(6.42)$ & $18(8.82)$ & $42(8.45)$ \\
Social interaction problems & $14(29.79)$ & $1(3.57)$ & $123(56.42)$ & $130(63.73)$ & $268(53.92)$ \\
Limited interests, repetitive behaviors & $0(0.00)$ & $3(10.71)$ & $44(20.18)$ & $22(10.78)$ & $69(13.88)$ \\
Unusual reactivity to sensory input & $0(0.00)$ & $10(35.71)$ & $8(3.67)$ & $3(1.47)$ & $21(4.23)$ \\
Other & $0(0.00)$ & $8(28.57)$ & $1(0.46)$ & $1(0.49)$ & $10(2.01)$ \\
Missing & $11(23.40)$ & $5(17.86)$ & $4(1.83)$ & $16(7.84)$ & $36(7.24)$ \\
Total & $47(100)$ & $28(100)$ & $218(100)$ & $204(100)$ & $497(100)$ \\
\hline
\end{tabular}

ASD: Autism Spectrum Disorder

Table 6. Reasons why a child was thought not to have ASD [frequency (\%)]

\begin{tabular}{|c|c|c|c|c|c|}
\hline Response & $\begin{array}{c}\text { Primary } \\
\text { medical center }\end{array}$ & $\begin{array}{l}\text { Public } \\
\text { institutions }\end{array}$ & $\begin{array}{l}\text { Educational } \\
\text { institutions }\end{array}$ & $\begin{array}{l}\text { Treatment } \\
\text { institutions }\end{array}$ & Total \\
\hline Able to make eye-contact with family & $7(14.9)$ & $0(0.0)$ & $41(18.8)$ & $18(8.8)$ & $66(13.3)$ \\
\hline Satisfactory language development & $7(14.89)$ & $1(3.57)$ & $21(9.63)$ & $16(7.84)$ & $45(9.05)$ \\
\hline Satisfactory intelligence & $1(2.13)$ & $1(3.57)$ & $13(5.96)$ & $12(5.88)$ & $27(5.43)$ \\
\hline Able to express emotions & $2(4.26)$ & $3(10.71)$ & $37(16.97)$ & $30(14.71)$ & $72(14.49)$ \\
\hline $\begin{array}{l}\text { According to parent report able to play } \\
\text { with siblings or friends }\end{array}$ & $9(19.15)$ & $10(35.71)$ & $20(9.17)$ & $33(16.18)$ & $72(14.49)$ \\
\hline No limited interest and repetitive behaviors & $1(2.13)$ & $8(28.57)$ & $27(12.39)$ & $31(15.20)$ & $67(13.48)$ \\
\hline No unusual reactivity to sensory input & $0(0.00)$ & $0(0.00)$ & $4(1.83)$ & $2(0.98)$ & $6(1.21)$ \\
\hline Able to make positive attachment with family & $7(14.89)$ & $3(10.71)$ & $15(6.88)$ & $36(17.65)$ & $61(12.27)$ \\
\hline Able to ask for what he/she needs & $1(2.13)$ & $0(0.00)$ & $19(8.72)$ & $2(0.98)$ & $22(4.43)$ \\
\hline Other & $2(4.26)$ & $1(3.57)$ & $11(5.05)$ & $7(3.43)$ & $21(4.23)$ \\
\hline Missing & $10(21.28)$ & $1(3.57)$ & $10(4.59)$ & $17(8.33)$ & $38(7.65)$ \\
\hline Total & $47(100)$ & $28(100)$ & $218(100)$ & $204(100)$ & $497(100)$ \\
\hline
\end{tabular}

ASD: Autism Spectrum Disorder

Table 7. ASD early screening tool equipped [frequency (\%)]

\begin{tabular}{lccccc}
\hline Response & Primary medical center & Public institutions & Educational institutions & Treatment institutions & Total \\
\hline Yes & $15(22.06)$ & $23(51.11)$ & $4(1.33)$ & $98(37.69)$ & $140(20.77)$ \\
No & $52(76.47)$ & $22(48.89)$ & $15(4.98)$ & $150(57.69)$ & $239(35.46)$ \\
Missing & $1(1.47)$ & $0(0.00)$ & $282(93.69)$ & $12(4.62)$ & $295(43.77)$ \\
Total & $68(100)$ & $45(100)$ & $301(100)$ & $260(100)$ & $674(100)$ \\
\hline
\end{tabular}

ASD: Autism Spectrum Disorder

Table 8. Mainly used ASD early screening tool [frequency (\%)]

\begin{tabular}{lccccc}
\hline \multicolumn{1}{c}{ Response } & Primary medical center & Public institutions & Educational institutions & \multicolumn{1}{c}{ Treatment institutions } & \multicolumn{1}{c}{ Total } \\
\hline K-DST & $10(66.67)$ & $4(17.39)$ & $2(50.00)$ & $6(6.12)$ & $22(15.71)$ \\
CARS & $3(20.00)$ & $1(4.35)$ & $2(50.00)$ & $88(89.80)$ & $94(67.14)$ \\
CBCL & $0(0.00)$ & $5(21.74)$ & $0(0.00)$ & $0(0.00)$ & $5(3.57)$ \\
SCQ & $1(6.67)$ & $13(56.52)$ & $0(0.00)$ & $0(0.00)$ & $14(10.00)$ \\
Other & $1(6.67)$ & $0(0.00)$ & $0(0.00)$ & $1(1.02)$ & $2(1.43)$ \\
Missing & $0(0.00)$ & $0(0.00)$ & $0(0.00)$ & $3(3.06)$ & $3(2.14)$ \\
Total & $15(100)$ & $23(100)$ & $4(100)$ & $98(100)$ & $140(100)$ \\
\hline
\end{tabular}

ASD: Autism Spectrum Disorder, CARS: Childhood Autism Rating Scale, CBCL: Child Behavior Checklist, K-DST: Korean Developmental Screening Test, SCQ: Social Communication Questionnaire 
차진료기관, 교육기관, 치료기관은 '비치되어 있지 않다’고 한 경우가 각각 $76.47,4.98,57.69 \%$ 로 더 높았고, 공공기관만이 '비치되어 있다'고 한 경우가 51.11\%로 더 많았다(Table 7). 또, 도구가 비치되어 있다고 응답한 경우에 한하여, 주로 어떠한 도구를 사용하는지 묻는 질문에는 일차진료기관은 Korean Developmental Screening Test(K-DST)가 66.67\%, 공공기관 은 Social Communication Questionnaire(SCQ)가 56.52\%, 치
료기관은 Childhood Autism Rating Scale(CARS)이 89.80\% 로 가장 많았고, 교육기관은 K-DST와 CARS가 가장 많았으 나(각각 50\%) 그 비율이 매우 낮은 편이었다(Table 8).

\section{ASD 아동 발견 시 조치 실태}

기관에 $\mathrm{ASD}$ 아동이 방문했던 경험이 있는 자에 한하여 $\mathrm{ASD}$ 아동을 발견했을 때 취하는 조치에 대해 물어본 결과, 네 집단

Table 9. Actions taken when a child is suspected to have ASD [frequency (\%)]

\begin{tabular}{|c|c|c|c|c|c|}
\hline Response & $\begin{array}{c}\text { Primary } \\
\text { medical center }\end{array}$ & $\begin{array}{c}\text { Public } \\
\text { institutions }\end{array}$ & $\begin{array}{l}\text { Educational } \\
\text { institutions }\end{array}$ & $\begin{array}{l}\text { Treatment } \\
\text { institutions }\end{array}$ & Total \\
\hline Do a follow-up assessment by oneself & $3(6.38)$ & $0(0.00)$ & $14(6.42)$ & $33(16.18)$ & $50(10.06)$ \\
\hline Recommend to visit a hospital & $32(68.09)$ & $20(71.43)$ & $156(71.56)$ & $122(59.80)$ & $330(66.40)$ \\
\hline Recommend to visit a private (child) psychiatry clinic & $8(17.02)$ & $5(17.86)$ & $0(0.00)$ & $15(7.35)$ & $28(5.63)$ \\
\hline Recommend to visit a children's center & $1(2.13)$ & $3(10.71)$ & $0(0.00)$ & $9(4.41)$ & $13(2.62)$ \\
\hline No further actions taken & $1(2.13)$ & $0(0.00)$ & $40(18.35)$ & $6(2.94)$ & $47(9.46)$ \\
\hline Other & $0(0.00)$ & $0(0.00)$ & $5(2.29)$ & $14(6.86)$ & $19(3.82)$ \\
\hline Missing & $2(4.26)$ & $0(0.00)$ & $3(1.38)$ & $5(2.45)$ & $10(2.01)$ \\
\hline Total & 47 (100) & $28(100)$ & $218(100)$ & $204(100)$ & 497 (100) \\
\hline
\end{tabular}

ASD: Autism Spectrum Disorder

Table 10. Actions taken to report to parents when a child is suspected of ASD [frequency (\%)]

\begin{tabular}{|c|c|c|c|c|c|}
\hline Response & $\begin{array}{c}\text { Primary } \\
\text { medical center }\end{array}$ & $\begin{array}{c}\text { Public } \\
\text { institutions }\end{array}$ & $\begin{array}{l}\text { Educational } \\
\text { institutions }\end{array}$ & $\begin{array}{l}\text { Treatment } \\
\text { institutions }\end{array}$ & Total \\
\hline Tell parents that their child is suspected of ASD & $10(21.28)$ & $19(67.86)$ & $11(5.05)$ & $84(41.18)$ & $124(24.95)$ \\
\hline Tell parents that their child has development delay & $28(59.57)$ & $6(21.43)$ & $100(45.87)$ & $68(33.33)$ & $202(40.64)$ \\
\hline Don't say anything because accurate diagnosis is difficult & $3(6.38)$ & $0(0.00)$ & $10(4.59)$ & $3(1.47)$ & $16(3.22)$ \\
\hline Advice parents on actions they can take & $3(6.38)$ & $2(7.14)$ & $84(38.53)$ & $32(15.69)$ & $121(24.35)$ \\
\hline Other & $1(2.13)$ & $1(3.57)$ & $13(5.96)$ & $16(7.84)$ & $31(6.24)$ \\
\hline Missing & $2(4.26)$ & $0(0.00)$ & $0(0.00)$ & $1(0.49)$ & $3(0.60)$ \\
\hline Total & $47(100)$ & $28(100)$ & $218(100)$ & $204(100)$ & $497(100)$ \\
\hline
\end{tabular}

ASD: Autism Spectrum Disorder

Table 11. Necessity of developing an early screening tool [frequency (\%)]

\begin{tabular}{|c|c|c|c|c|c|}
\hline Response & Primary medical center & Public institutions & Educational institutions & Treatment institutions & Total \\
\hline Yes & 53 (77.94) & $41(91.11)$ & 288 (95.68) & 244 (93.85) & $626(92.88)$ \\
\hline No & $9(13.24)$ & $4(8.89)$ & $11(3.65)$ & $14(5.38)$ & $38(5.64)$ \\
\hline Missing & $6(8.82)$ & $0(0.00)$ & $2(0.66)$ & $2(0.77)$ & $10(1.48)$ \\
\hline Total & $68(100)$ & 45 (100) & 301 (100) & $260(100)$ & $674(100)$ \\
\hline
\end{tabular}

Table 12. The reason why it is important to develop an early screening tool [frequency (\%)]

\begin{tabular}{|c|c|c|c|c|c|}
\hline Response & $\begin{array}{c}\text { Primary } \\
\text { medical center }\end{array}$ & $\begin{array}{c}\text { Public } \\
\text { institutions }\end{array}$ & $\begin{array}{l}\text { Educational } \\
\text { institutions }\end{array}$ & $\begin{array}{l}\text { Treatment } \\
\text { institutions }\end{array}$ & Total \\
\hline There is no appropriate early screening tool in our country & $14(20.59)$ & $5(11.11)$ & $31(10.30)$ & $17(6.54)$ & $67(9.94)$ \\
\hline The existing early screening tools aern't suitable & $11(16.18)$ & $5(11.11)$ & $57(18.94)$ & $36(13.85)$ & $109(16.17)$ \\
\hline $\begin{array}{l}\text { There is a need of an early screening tool that can } \\
\text { reliably discriminate ASD }\end{array}$ & $22(32.35)$ & $29(64.44)$ & $181(60.13)$ & $178(68.46)$ & $410(60.83)$ \\
\hline Other & $5(7.35)$ & $2(4.44)$ & $15(4.98)$ & $6(2.31)$ & $28(4.15)$ \\
\hline Missing & $16(23.53)$ & $4(8.89)$ & $17(5.65)$ & $23(8.85)$ & $60(8.90)$ \\
\hline Total & $68(100)$ & $45(100)$ & $301(100)$ & $260(100)$ & $674(100)$ \\
\hline
\end{tabular}

ASD: Autism Spectrum Disorder 
Table 13. Conditions new early screening tools should meet [frequency (\%)]

\begin{tabular}{|c|c|c|c|c|c|}
\hline Response & $\begin{array}{c}\text { Primary } \\
\text { medical center }\end{array}$ & $\begin{array}{c}\text { Public } \\
\text { institutions }\end{array}$ & $\begin{array}{l}\text { Educational } \\
\text { institutions }\end{array}$ & $\begin{array}{l}\text { Treatment } \\
\text { institutions }\end{array}$ & Total \\
\hline Anyone should be able to use it & $22(32.35)$ & $13(28.89)$ & $101(33.55)$ & $20(7.69)$ & $156(23.15)$ \\
\hline The assessment time must be short & $15(22.06)$ & $0(0.00)$ & $4(1.33)$ & $15(5.77)$ & $34(5.04)$ \\
\hline Must be able to assess different age groups & $0(0.00)$ & $0(0.00)$ & $10(3.32)$ & $7(2.69)$ & $17(2.52)$ \\
\hline Must be able to assess different age groups specifically & $6(8.82)$ & $4(8.89)$ & $60(19.93)$ & $42(16.15)$ & $112(16.62)$ \\
\hline Must be able to reliably discriminate ASD & $14(20.59)$ & $24(53.33)$ & $71(23.59)$ & $123(47.31)$ & $232(34.42)$ \\
\hline Must be able to discriminate ASD from other disorders & $1(1.47)$ & $2(4.44)$ & $7(2.33)$ & $27(10.38)$ & $37(5.49)$ \\
\hline $\begin{array}{l}\text { If a child is suspected to have ASD necessary information } \\
\text { must be given to his/her parents }\end{array}$ & $2(2.94)$ & $2(4.44)$ & $44(14.62)$ & $19(7.31)$ & $67(9.94)$ \\
\hline Must receive fees for ASD assessment & $3(4.41)$ & $0(0.00)$ & $0(0.00)$ & $0(0.00)$ & $3(0.45)$ \\
\hline Other & $0(0.00)$ & $0(0.00)$ & $1(0.33)$ & $3(1.15)$ & $4(0.59)$ \\
\hline Missing & $5(7.35)$ & $0(0.00)$ & $3(1.00)$ & $4(1.54)$ & $12(1.78)$ \\
\hline Total & $68(100)$ & $45(100)$ & $301(100)$ & $260(100)$ & $674(100)$ \\
\hline
\end{tabular}

ASD: Autism Spectrum Disorder

Table 14. Types of treatment service provided to infants suspected of ASD

\begin{tabular}{lc}
\hline \multicolumn{1}{c}{ Response } & Frequency (\%) \\
\hline Psychotherapy (playtherapy) & $50(19.23)$ \\
Developmental play (theraplay) & $67(25.77)$ \\
Art therapy (music, art, physical education) & $12(4.62)$ \\
Sensory integration therapy & $16(6.15)$ \\
Cognitive therapy & $5(1.92)$ \\
Learning therapy & $27(10.38)$ \\
Language therapy & $14(5.38)$ \\
Social skills training (individual, group and other) & $1(0.38)$ \\
Behavioral therapy & $1(0.38)$ \\
Rehabilitation & $1(0.38)$ \\
Family therapy and service for family & $6(2.31)$ \\
members (parent education) & \\
Other & $60(23.08)$ \\
Missing & $260(100)$ \\
\hline ASD: Autism Spectum Disorder
\end{tabular}

ASD: Autism Spectrum Disorder

모두 ‘큰 병원에 가보라’고 하는 경우가 가장 많았고(68.09, $71.43,71.56,59.80 \%)$, 일차진료기관과 공공기관은 '개인(소아) 정신과에 가 보라 권한다(17.02, 17.86\%)', 교육기관은 '별다른 조치를 하지 않는다( $16.61,8.61 \%)$, 치료기관은 '직접 추적관찰 한다(16.18\%)'가 그 다음으로 높았다(Table 9). 그리고 부모에 게 어떻게 이야기하는지에 대해 물어본 결과, 일차진료기관과 교육기관은 '직접적으로 애기하지 않고 발달이 늦는 것 같다 고 말한다(59.57, 45.87\%)', 공공기관과 치료기관은 '자폐증이 의심된다고 말한다 $(67.86,41.18 \%)^{\prime}$ 가 가장 많은 것으로 나타났 다(Table 10).

\section{선별도구에 대한 생각}

선별도구 개발에 대한 생각에 대해 물은 결과, 모든 집단이
Table 15. Categories of treatment service provided to infants suspected of ASD

\begin{tabular}{lc}
\hline \multicolumn{1}{c}{ Response } & Frequency (\%) \\
\hline Individual therapy & $133(51.15)$ \\
Group therapy & $15(5.77)$ \\
Individual and group therapy & $48(18.46)$ \\
Other & $7(2.69)$ \\
Missing & $57(21.92)$ \\
Total & $260(100)$ \\
\hline
\end{tabular}

ASD: Autism Spectrum Disorder

선별도구의 개발이 필요하다고 응답하였다(Table 11). 선별도구 개발이 필요한 이유에 대해서는 네 집단 모두 "보다 변별력을 높 이는 것이 필요하다를 선택하였다(32.35, 64.44, 60.13, 68.46\%) (Table 12). 한편 개발될 선별도구의 조건으로는 일차진료기 관, 교육기관에서 '누구나 쉽게 사용할 수 있어야 한다(32.35, $33.55 \%$ )'가 가장 많았고, 공공기관과 치료기관은 '자폐증의 변 별력이 높아야 한다(53.33, 47.31\%)'가 가장 많았다(Table 13).

\section{치료실태}

$\mathrm{ASD}$ 영유아의 치료실태에 대해 살펴보기 위해, 치료기관 에 한정하여 치료 서비스 종류(Table 14)와 유형(Table 15)에 대해 질문하였다. 그 결과, 치료 서비스 종류로는 발달놀이 (25.77\%)가 가장 많았고, 그 다음으로는 심리치료(19.23\%)가 가장 많았다. 치료 유형은 개인치료(51.15\%)가 가장 많았고, 그 다음으로는 개인치료와 집단치료를 병행(18.46\%)하는 경우가 가장 많았다.

\section{고 찰}

본 연구는 $\mathrm{ASD}$ 를 접할 수 있는 관련 기관 종사자, 즉 일차 
진료기관, 공공기관, 교육기관, 치료기관의 종사자들을 대상 으로 $\mathrm{ASD}$ 의 조기선별과 관련된 지식과 인식에 대해 조사하 였다. 조사결과, 아직까지 현장에서 영유아 $\mathrm{ASD}$ 와 관련된 지 식과 인식이 부족한 실정이며, 조기선별을 위한 준비가 잘 마 련되어 있지 못한 상태로 판단되는 바, 관련 분야 종사자들의 지식 및 인식개선과 더불어 조기진단을 위한 실질적인 대책을 마련하는 것이 필요한 것으로 생각되었다. 조사결과에 대한 구체적인 논의는 다음과 같다.

첫째, 기관 종사자들의 ASD 관련 지식 실태와 관련하여, 기 관별로 지식의 차이가 있는 것으로 나타났으나, 전반적으로 $\mathrm{ASD}$ 에 대한 인식이 부족한 것으로 판단되었다. 구체적으로 살펴보면, $\mathrm{ASD}$ 로 처음 진단 가능한 연령에 대해 물었을 때 대 부분의 관련 종사자들이 '2세 미만'에서 '4세 미만'을 적절한 연령이라고 선택하여 $\mathrm{ASD}$ 의 증상이 이른 시기에 시작된다는 인식은 어느 정도 갖추어진 상태인 것으로 예상되었다. 그러 나, 공공기관이나 치료기관에 종사하고 있는 인력들의 경우, '4세 미만'이라고 응답한 경우가 상대적으로 많은 편이었으며, 특히 치료기관의 경우 ‘6세 미만’이라고 응답한 경우도 $15.77 \%$ 에 달하였던 바, 일부 관련 종사자들은 $\mathrm{ASD}$ 증상이 조기에 발견될 수 있다는 것에 대해 잘 인지하지 못하는 것으로 추정 되었다. 또한 응답자의 수가 상대적으로 적은 편이긴 하였지 만, 현재 영유아 건강검진 실시자로서 영유아 $\mathrm{ASD}$ 의 조기진 단에 가장 핵심적인 역할을 해야 하는 일차의료기관 종사자 들조차 '2세 미만'이라고 응답한 경우가 35.29\%, '1세 미만'이 라고 응답한 경우가 $5.88 \%$ 로 타 기관과 큰 차이를 보이지 않는 수준이라는 점도 주목할 만하다. ASD 진단 가능 연령에 대한 인식의 경우 기관에 왕래하는 영유아가 적절한 진단과 개입 으로 이어지도록 하는 데 가장 중요한 역할을 담당하므로 더 욱 우려가 된다. 따라서 앞으로 관련 기관 종사자들에게 $\mathrm{ASD}$ 증상이 전형적으로는 12 24개월 사이에, 또 심각한 경우 12 개 월 이전에도 발견될 수 있음에 대해 안내하고 교육하는 과정 이 반드시 필요하겠으며, 이를 위해 적절한 교육 및 홍보 방안 을 마련하여 체계적인 변화를 도모해야 하겠다.

한편, $\mathrm{ASD}$ 라고 판단할 수 있는 기준이나 징후에 대해서도 대부분의 기관 종사자가 '사회적 관심, 상호작용 문제'를 중요 한 징후로 선택하여 핵심적인 증상에 대해서는 인식이 갖추 어진 것으로 생각되었으나, 공공기관의 경우 '자극에 대한 과 소, 과대 반응을 가장 중요한 징후로 꼽은 사람이 28명 중 10 명으로 $\mathrm{ASD}$ 의 중요한 특징이 무엇인지 잘 인식하지 못하고 있는 경우도 많은 것으로 생각되었다. 그리고 '사회적 관심, 상 호작용 문제'가 가장 중요하다고 선택한 일차진료기관 종사자 들의 경우에도 '언어적 의사표현 손상'과 '비언어적 의사표현 손상'이 가장 중요한 징후라고 선택한 사람이 각각 27.66,
$19.15 \%$ 로 나타나, 적지 않은 비율이 $\mathrm{ASD}$ 의 증상을 단편적으 로만 이해하고 있음을 알 수 있었다. 마지막으로 $\mathrm{ASD}$ 가 아니 라고 판단했던 기준이나 징후에 대해 물었을 때, 일차진료기 관과 공공기관은 ‘부모보고에 의하면, 형제자매, 친구와 놀이 할 수 있다고 하였다를 가장 많이 선택하였고, 교육기관은 '가족과 눈맞춤이 가능하였다', 치료기관은 '제한된 관심, 반복 적이고 상동적인 행동이 없었다를 가장 많이 선택하였다. 그 러나, $\mathrm{ASD}$ 는 장애 명칭에서 알 수 있듯이 증상과 징후에 상당 한 범위(spectrum)가 존재하기에, 동일한 장애로 진단을 받더 라도 매우 다양한 양상과 문제행동을 보이게 된다. 따라서 어 떠한 경우에는 사회적 의사소통 및 상호작용의 손상이 매우 경하여서 다소 부자연스러운 측면이 있더라도 때때로 언어적, 비언어적 의사소통을 주고받거나 일부 친밀한 대상과 관계를 맺고 유지하기도 한다. 또, 제한적이고 반복적인 행동이나 흥 미, 활동의 경우 $\mathrm{ASD}$ 의 특징적인 행동양상이기는 하지만, 이러 한 행동문제가 미약하여 잘 관찰되지 않거나 전형적인 양상 에서 벗어나 판단하기 어려운 경우도 흔하다. 따라서 앞서 관 련 종사자들이 선택한 단편적인 증상의 부재로 $\mathrm{ASD}$ 가 아니라 고 판단하는 것은 상당한 무리가 있다고 하겠다. 이러한 결과 를 종합해 보았을 때, 관련 분야 종사자들이 일부 증상의 유 무를 통해 ASD 조기진단을 위한 조치를 적절히 취하지 않을 가능성이 농후한 상태임을 알 수 있어 적절한 교육과 인식개 선이 필요해 보인다.

둘째, $\mathrm{ASD}$ 선별 실태와 관련하여, 각 기관별로 근무하고 있는 기관에 영유아 ASD 선별도구가 비치되어 있는지 물었 을 때, '없다라고 응답한 경우가 대다수를 차지하였으며, 그중 에서도 조기선별에 중추적인 역할을 하는 일차진료기관에서 선별도구가 비치되어 있지 않다고 응답한 비율이 가장 높게 나타났다. 이는 $\mathrm{ASD}$ 의 조기선별을 위해 필요한 준비가 잘 마 련되어 있지 않은 현장의 실태를 잘 반영한다고 하겠으며, 지 금까지 영유아 $\mathrm{ASD}$ 의 조기진단이 나날이 강조되어 왔음에 도 불구하고 실질적인 진단은 늦춰지고 있는 이유를 일부 설 명한다고 할 수 있다. 재차 강조하였듯이 $\mathrm{ASD}$ 의 치료적 개입 은 최대한 이른 시기에 이루어져야 한다. 따라서 증상이 의심 될 경우 기관 내에서 빠르게 이를 평정해 볼 수 있는 선별도 구가 비치되어 있는 것이 매우 중요한 역할을 할 것이다. 특히 일차진료기관의 경우 영유아 건강검진으로 인해 조기에 $\mathrm{ASD}$ 를 발견하기 좋은 조건을 가지고 있는 기관이기에 선별도구의 비치를 권고하는 것이 필요해 보인다. 한편, 기관별로 가장 많 이 사용하는 선별도구에 대해 물었을 때, 일차진료기관은 한 국영유아발달선별검사 $(\mathrm{K}-\mathrm{DST})$ 를, 공공기관은 사회적 의사소 통 설문지(SCQ)를, 치료기관은 아동기 자폐증 평정척도(CARS) 를 가장 많이 선택하였으며, 교육기관은 무응답 비율이 높아 
조사결과에 큰 의미를 부여하기 어려웠다. 이러한 도구들이 $\mathrm{ASD}$ 를 조기에 선별하기 위해 상당 부분 기여를 하고 있는 것 은 사실이나, 각 도구의 특성상 여러 가지 제한점이 여전히 존 재한다. K-DST의 경우 4개월의 매우 어린 영아부터 이 도구를 사용할 수 있다는 점에서 '선별' 도구로서 큰 역할을 하고 있는 것은 확실하나, 전반적인 발달 지표에 대한 위치를 평정하는 도구이기에 미묘하고 다양한 $\mathrm{ASD}$ 증상을 선별해 내는 데 어 려움이 따르는 것이 사실이다. 또 사회적 의사소통 설문지의 경우 아직까지 국내에서 표준화 작업이 이루어지지 않은 도구 이기에 앞으로 더 많은 연구가 필요한 상태이며 ${ }^{18)} \mathrm{CARS}$ 의 경 우도 전 연령을 대상으로 사용할 수 있다고 되어 있으나, 전체 평가 문항의 수가 적고 면밀하지 못한 경향이 있어 어린 영유 아나, 경한 $\mathrm{ASD}$ 증상을 보이는 경우 효율적으로 증상을 평정 해 내는 데 어려움이 있다. ${ }^{19)}$ 따라서 차후 이러한 제한점을 보 완할 수 있는 보다 효율적인 조기선별도구의 개발이 도움이 될 것이라 생각된다.

셋째, ASD 발견 시 조치에 대해 물었을 때, 모든 관련 종사 자가 '큰 병원에 가 보라 권한다’라고 응답한 경우가 가장 많았 다. 또 부모에게 어떻게 말하는지에 대해서는 '직접적으로 야 기하지 않고 발달이 늦는 것 같다고 말한다를 가장 많이 꼽 았다. 이러한 응답을 보았을 때, 기관별로 어느 정도의 차이는 있을 수 있으나, 현재로서는 기관 내에서 적절한 조치가 신속 하게 이루어지지 못하고 있음을 추측할 수 있다. 즉, 기관 내에 서 $\mathrm{ASD}$ 증상을 보다 상세하게 검토하기보다는 다른 기관에 연계하는 조치가 주를 이루고 있고, 부모에게도 적절한 소견 을 보고하기보다는 직접적인 표현을 피하는 경향이 있음을 알 수 있다. 이로 인해 영유아 $\mathrm{ASD}$ 의 조기진단을 늦추게 될 뿐만 아니라, 자녀의 증상에 대해 확신이 없는 부모들의 혼란 을 가중시킬 위험이 있다는 점에서 주의를 요한다. 따라서 관 련 기관 종사자들의 $\mathrm{ASD}$ 조기발견 시 적절한 조치 방법에 대해 안내하고 $\mathrm{ASD}$ 가 치료적 개입이 신속하게 있을 경우 증 상의 완화를 기대할 수 있는 장애임을 교육시키는 것이 필요 해 보인다.

넷째, 선별도구 개발에 대한 생각을 알아보기 위해, 선별도 구 개발이 필요한지 물었을 때 모든 기관이 '필요하다'고 응답 하였고, 그 이유로 '보다 변별력을 높이는 것이 필요하다'라고 응답하였던 바, 현재 각기 분야에서 $\mathrm{ASD}$ 증상을 평정하기 위 한 적절한 도구의 부재로 많은 어려움을 겪고 있는 것으로 판 단되었다. 또, 도구 개발 시 선별도구가 갖추어야 하는 조건에 대해서는 일차진료기관, 교육기관이 '누구나 쉽게 사용할 수 있어야 한다'를 선택하였고, 공공기관, 치료기관은 '자폐증의 변별력을 높여야 한다를 선택하였다. 이에 새로운 도구 개발 을 위해서, 효율적으로 증상을 평정하는 도구의 효율성뿐만
아니라, 다양한 분야의 종사자가 간단한 교육과 훈련을 통해 서 손쉽고 간편하게 사용할 수 있는 도구를 제작하는 것도 중 요한 사안임을 알 수 있다.

다섯째, 치료 현황과 관련하여서는 대부분의 $\mathrm{ASD}$ 치료가 개별치료로 이루어지고 있으며, 치료 서비스의 종류로는 발달 놀이, 심리치료가 가장 많고, 학습치료, 감각통합치료가 그 다 음을 차지하는 것으로 나타났다. 사실상 $\mathrm{ASD}$ 의 증상완화 및 적응 개선을 위해 가장 많은 근거가 마련되어 있는 치료기법 은 행동치료적 기법과,32,21) 사회성 훈련인 데에 비하여,22,23) 발 달놀이나 심리치료는 그 근거가 확립되지 않고 사례보고 수 준에 그치고 있다. 특히 감각통합치료의 경우 적절한 이론적 인 근거나 사례발표 연구도 이루어지고 있지 못한 실정이다. ${ }^{24)}$ $\mathrm{ASD}$ 증상의 개선을 위하여 다양한 치료적 접근을 시도하는 것이 도움이 될 수도 있겠으나, 근거에 기반한 치료를 우선적 으로 시행하여야 할 것이다. 근거에 기반하지 않은 여러 가지 치료기법은 증상개선에 효과가 미약하거나 오히려 부정적인 영향을 미칠 위험도 있으므로 주의를 기울여야 하겠다. 근거 기반의 치료에 대한 관련 분야 종사자들의 인식의 변화가 필 요하겠으며, 현재 활용되고 있는 치료기법에 대한 이론적인 배경과 사례연구도 활발히 진행되어야 할 것이다.

마지막으로 본 연구의 제한점은 다음과 같다.

첫째, 설문 응답 대상과 관련하여, 일차진료기관, 공공기관, 교육기관, 치료기관의 기관별 비율에 차이가 있어 교육기관과 치료기관 종사자의 비율이 상대적으로 많은 편이었다. 또 직 종 특성이긴 하나 대부분의 응답자가 여성이었다는 점에서도 균일한 표본의 표집 과정에서 어려움이 있었다고 하겠다. 이 에 본 연구결과를 일반화하기에는 다소 제한점이 존재한다.

둘째, 일차의료기관 종사자의 응답을 포함한 일부 질문지 항목에서 무응답 비율이 높은 항목이 존재하는데, 본 연구가 자폐스펙트럼장애에 대한 전문적 지식을 갖추고 있지 않은 준전문가 집단을 대상으로 한다는 점에서, 본 연구진이 제작 한 질문지의 높은 난이도로 인한 응답의 어려움이 존재했을 것으로 예상된다. 본 연구진이 이를 우려하여 전반적인 질문 지 내용을 여러 차례 검토하였음에도 불구하고 이러한 제한 점이 시사되었기에, 차후 유사, 후속 연구에서는 연구대상이 질 문지의 내용을 보다 쉽게 이해할 수 있도록 조정하고, 예비조 사를 통해 대상자가 질문지의 내용을 이해하는 데 어려움이 없는지 충분히 검토하는 것이 도움이 되겠다.

셋째, 기관별로 실태의 차이가 있는지 집단 간 비교를 실시 하고자 하였으나, 집단의 규모 차이가 크고 설문지의 범주가 많은 편이어서 집단별 분석을 실시하는 데 제한점이 있었다. 이에 후속 연구에서는 본 연구에서 검토한 실태가 집단별로 유 의한 차이를 보이는지 확인해 보는 것도 기초적인 자료 마련에 
도움이 될 것으로 보인다.

\section{결 론}

본 연구는 $\mathrm{ASD}$ 조기진단과 개입을 위해 여러 기관 종사자 들의 인식과 의견을 조사하여 추후 연구에 기초적인 자료를 마련했다는 점에서 큰 의의가 있다고 하겠다. 연구결과를 종 합하여 보았을 때, 아직까지 현장에서 $\mathrm{ASD}$ 조기진단과 개입 에 대한 인식과 지식이 잘 마련되고 있지 않으므로 지속적인 인식개선과 교육이 요구되겠으며, 빠른 시일 내에 ASD 조기 개입을 위한 영유아기 $\mathrm{ASD}$ 조기선별도구 개발의 필요성도 대두된다고 하겠다.

중심 단어:자폐스펙트럼장애; 조기진단; 종사자 인식.

\section{Acknowledgments}

본 연구는 한국보건산업진흥원의 사회서비스 R\&D 사업(연구번호 $\mathrm{HI} 14 \mathrm{C} 2719)$ 의 연구비 지원에 의해 수행되었음.

\section{Conflicts of Interest}

The authors have no financial conflicts of interest.

\section{REFERENCES}

1) American Psychiatric Association. Diagnostic and Statistical Manual of Mental Disorders (DSM-5®). 5th ed. Washington, DC: American Psychiatric Association;2013.

2) Kim YS, Leventhal BL, Koh YJ, Fombonne E, Laska E, Lim EC, et al. Prevalence of autism spectrum disorders in a total population sample. Am J Psychiatry 2011;168:904-912.

3) Dawson G, Rogers S, Munson J, Smith M, Winter J, Greenson J, et al. Randomized, controlled trial of an intervention for toddlers with autism: the early start denver model. Pediatrics 2010;125:e17-e23.

4) Drew A, Baird G, Baron-Cohen S, Cox A, Slonims V, Wheelwright $S$, et al. A pilot randomised control trial of a parent training intervention for pre-school children with autism. Preliminary findings and methodological challenges. Eur Child Adolesc Psychiatry 2002; 11:266-272.

5) Jocelyn LJ, Casiro OG, Beattie D, Bow J, Kneisz J. Treatment of children with autism: a randomized controlled trial to evaluate a caregiver-based intervention program in community day-care centers. J Dev Behav Pediatr 1998;19:326-334

6) Aldred C, Green J, Adams C. A new social communication intervention for children with autism: pilot randomised controlled treatment study suggesting effectiveness. J Child Psychol Psychiatry 2004; 45:1420-1430.

7) Dawson G. Early behavioral intervention, brain plasticity, and the prevention of autism spectrum disorder. Dev Psychopathol 2008; 20:775-803.
8) American Psychiatric Association. Diagnostic and Statistical Manual of Mental Disorders. 4th ed. Washington, DC: American Psychiatric Association;1994.

9) Baron-Cohen S, Cox A, Baird G, Swettenham J, Nightingale N, Morgan K, et al. Psychological markers in the detection of autism in infancy in a large population. Br J Psychiatry 1996;168:158-163.

10) Turner LM, Stone WL, Pozdol SL, Coonrod EE. Follow-up of children with autism spectrum disorders from age 2 to age 9. Autism 2006;10:243-265.

11) Young RL, Brewer N, Pattison C. Parental identification of early behavioural abnormalities in children with autistic disorder. Autism 2003; 7:125-143

12) Shin MS, Kim HJ, Jang HJ, Jeon HS. A study of behavioral problems and coping strategies in children with developmental disorder. J Speech Lang Hear Disord 2015;24:121-135.

13) Lee SH, Lee S, Yoon SA. A study of support system for facilitating early diagnosis and intervention for young children with autism spectrum disorders: based on the experiences and the perceptions of parents. J Korean Assoc Pers Autism 2013;13:167-199.

14) Cho JG. A study on parent's needs of special education related services for students with disabilities in the special school. J Spec Educ Rehabil Sci 2010;49:113-138.

15) Kim GH. The teachers' perspective on young children with autism. J Spec Educ Rehabil Sci 2013;52:1-21.

16) Korea National Institute for Special Education. 2014 study on the current status of special education [cited 2016 May 7]. Available from: http://www.nise.go.kr/boardCnts/view.do?boardID=137\&bo $\operatorname{ardSeq}=102520 \& l e v=0 \&$ searchType $=$ null $\&$ status $Y N=$ W $\&$ page $=6$ $\& \mathrm{~s}=$ nise $\& \mathrm{~m}=0101 \&$ opType $=\mathrm{N}$.

17) Lee KS, Yoon HS, Chung HS, Yoo HJ. A study on early screening of young children with autism spectrum disorder in Korea and its support system. J Korean Assoc Pers Autism 2015;15:93-120.

18) Kim JH, Sunwoo HJ, Park SB, Noh DH, Jung YK, Cho IH, et al. A validation study of the Korean version of Social Communication Questionnaire. J Korean Acad Child Adolesc Psychiatry 2015;26: 197-208.

19) Shin MS, Kim YH. Standardization study for the Korean version of Childhood Autism Rating Scale: reliability, validity and cut-off score. Korean J Clin Psychol 1998;17:1-15.

20) Virues-Ortega J, Julio FM, Pastor-Barriuso R. The TEACCH program for children and adults with autism: a meta-analysis of intervention studies. Clin Psychol Rev 2013;33:940-953.

21) Eldevik S, Hastings RP, Hughes JC, Jahr E, Eikeseth S, Cross S. Meta-analysis of early intensive behavioral intervention for children with autism. J Clin Child Adolesc Psychol 2009;38:439-450.

22) Yoo HJ, Bahn G, Cho IH, Kim EK, Kim JH, Min JW, et al. A randomized controlled trial of the Korean version of the PEERS(®) parent-assisted social skills training program for teens with ASD. Autism Res 2014;7:145-161.

23) Frankel F, Myatt R, Sugar C, Whitham C, Gorospe CM, Laugeson E. A randomized controlled study of parent-assisted children's friendship training with children having autism spectrum disorders. J Autism Dev Disord 2010;40:827-842.

24) Lang R, O'Reilly M, Healy O, Rispoli M, Lydon H, Streusand W, et al. Sensory integration therapy for autism spectrum disorders: a systematic review. Res Autism Spectr Disord 2012;6:1004-1018. 